\title{
Trend of Mantoux Positivity in a Tertiary Health Institution in Nigeria: A Secondary Data Analysis
}

\author{
Genevieve Edokwe ${ }^{1}$, Inumanye N. Ojule ${ }^{1}$, Alafaka Tobin ${ }^{2}$ \\ ${ }^{1}$ Department of Preventive and Social Medicine, Faculty of Clinical Sciences, University of Port Harcourt, Rivers State Nigeria \\ ${ }^{2}$ Centre for Health and Development, University of Port Harcourt, Rivers State Nigeria
}

*All correspondence to:

Ojule, Inumanye

Department of Preventive and Social Medicine,

Faculty of Clinical Sciences, University of Port Harcourt, Rivers State Nigeria

Email id inumanye.ojule@uniport.edu.ng

\begin{abstract}
Background: Mantoux test is the most widely used screening test that aid diagnosis of latent tuberculosis infection (LTBI) especially in resource poor countries. This study aimed to determine the seven year trend of Mantoux test result at the University of Port Harcourt Teaching Hospital, Rivers State Nigeria. Methods: A secondary data analysis was carried out on abstracted data from 2011 to 2017 in the Mantoux result register. Descriptive statistics was computed for all categorical variables. Chi-square of trend was used to assess significant differences in positivity. P-value less than 0.05 was considered significant. Results: Using a cut-off point of $\geq 10 \mathrm{~mm}$ diameter, a total of 5863 clients were screened for TB. Chi square for trends showed statistical significant decreasing proportion of significant Mantoux reaction status among clients over the study period. Conclusion: The study showed a high prevalence of negative Mantoux reaction compared to positive reaction. Trend analysis showed a notable downward plunge of significant Mantoux positivity. The trend was towards continuous reduction in Mantoux test result positivity suggesting a tailing of LTBI in this region.
\end{abstract}

Keywords: Tuberculosis, Mantoux test, trend, Hospital.

\section{Introduction}

Tuberculosis (TB) continues to be a significant public health issue, with major part of the disease burden resident in Africa. It remains the single leading cause of death from a curable infectious disease (Dye, 2006). The WHO reported that there are slightly short of a third of the 10.4 million incident TB disease cases globally, of which 6.2 million represent the men, 3.2 million women and 1 million children in 2015 (WHO, 2016). Due to her large population size and high HIV/AIDS prevalence, Nigeria is reported to have the highest TB burden in Africa and ranked $4^{\text {th }}$ in the world (WHO, 2016). Nigeria is also reported to be among the seven countries that accounted for the $64 \%$ of the new TB cases globally (WHO, 2017). Notably, more men contract $\mathrm{TB}$ and die from it compared to women, but TB can have serious repercussion for women, particularly during their reproductive years and during pregnancy (WHO, 2017).

TB elimination primarily rely on preventing incident cases and this is best accomplished by screening to identify individuals with latent TB infection (LTBI) and providing a suitable chemoprophylaxis to keep individuals from progressing to active TB (WHO, 2014).

Diverse cut off values have been proposed for describing a positive Mantoux with different distinct conditions. For instance, people with increased risk of progressing to $\mathrm{TB}$ such as people with HIV/AIDS, immunosuppressive therapy have a reduced cut-off value of $\geq 5 \mathrm{~mm}$. However, persons living in high TB incidence countries or persons at higher risk of exposure (such as health care workers, persons that reside in long-term care homes or patients with chronic ill health) recording induration of $\geq 10 \mathrm{~mm}$ is considered as positive Mantoux test. For those with low or no risks, an induration of $\geq 15 \mathrm{~mm}$ is considered positive (Ahmad, 2010).

A study aimed at obtaining the basal rate and trend of Mantoux positivity in Korea and to ascertain whether LTBI is decreasing or not indicated decline in trend of Mantoux positivity from $28.0 \%$ in 2005 to $15.3 \%$ in 2009 (Lee et al., (2014). While a retrospective study conducted on 3218 suspected tuberculosis patients screened by Mantoux test in the same southern Nigeria reported (47.6\%) positive Mantoux test results with $\geq 10 \mathrm{~mm}$ cut off? $64.0 \%$ males and $36.0 \%$ females (Okon et al,.2014).

Mantoux test like every other tests has its limitations such as laboratory techniques which impacts on the specificity and sensitivity. Others are effect of Bacille Calmette-Guérin (BCG) vaccine and influence of environmental mycobacteria. Despite these, the test still remains the most widely utilized screening method used to determine if an individual is infected with or has developed immune response to mycobacterium tuberculosis 


\section{International Journal of Innovative Research in Medical Science (IJIRMS) \\ Volume 04 Issue 01 Jan 2019, ISSN: 2455-8737, Imp. Factor - 4.102 \\ Available online at - www.ijirms.in}

infection (Linas, et al, 2011). Mantoux test is also a valuable tool for the screening of household contacts and suspected cases of TB in BCG vaccinated subjects and in population with high BCG vaccination coverage such as Nigeria (Adeyekun et al, 2010). A positive Mantoux reaction indicates that the reacting person has, at some earlier point in time, became infected with a Mycobacterium that has left an immunological imprint (Rieder, 2011).

\section{Methodology}

\section{Study Area}

The study was carried out at the DOTS clinic of the department of community medicine, University of Port Harcourt Teaching Hospital (UPTH). The hospital is a foremost tertiary hospital located in Southern Nigeria and has about 900 beds capacity.

\section{Study Design}

Descriptive, cross-sectional study design. Data was collected retrospectively.

\section{Inclusion Criteria}

All recorded Mantoux test results found in the Mantoux test result registers for the selected years of study in the University of Port Harcourt Teaching Hospital.

\section{Exclusion Criteria}

All incompletely filled entries in the register such as partial recording or those that did not turn up for the reading.

\section{Study Procedure}

A data extraction sheet was designed to collect variables such as; age, sex, results and year from the Mantoux test result register across the seven years under review.

The TST used purified protein (PPD) that was administered on the volar surface of the left forearm using 5Tuberculin Units (TU) in $0.1 \mathrm{ml}$ intradermally.

The result was read 72 hours after injection. The results were measured as the horizontal diameter of induration around the application site using the ball point pen method and recorded to the nearest millimeter.

\section{Data Analysis}

The Data provided in the Mantoux test result register were correctly copied into the data extraction sheet, entered into Microsoft excel sheet and analyzed using the SPSS software (version 23.0). Descriptive statistics were presented as frequencies and percentages. Chi-square test was employed to determine the association between variables while chi-square of trend was used to assess significant difference in proportion of significant Mantoux text result across the seven years under review. In this study, a positive Mantoux test is considered an induration $\geq 10$ diameter.

\section{Results}

A total of 5863 Mantoux tests results found eligible within the selected years of study were extracted from the Mantoux result register in the hospital within the selected years of study. The results of the analysis carried out are presented in tabular formats as shown below.

Socio-demographic characteristics.

Table 1: Age distribution of clients that were screened for tuberculosis from 2011- 2017

\begin{tabular}{|c|c|c|}
\hline Variable & Frequency $(\mathbf{N})$ & Percentage (\%) \\
\hline \multicolumn{3}{|c|}{ Age grouped (years) } \\
\hline$<1$ & 508 & 8.7 \\
\hline $1-10$ & 1542 & 26.3 \\
\hline $11-20$ & 570 & 9.7 \\
\hline $21-30$ & 1703 & 29.0 \\
\hline $31-40$ & 792 & 13.5 \\
\hline $41-50$ & 385 & 6.1 \\
\hline $51-60$ & 210 & 3.6 \\
\hline $61-70$ & 127 & 2.2 \\
\hline$>70$ & 53 & 0.9 \\
\hline Total & 5863 & 100.0 \\
\hline Mean age & \multicolumn{2}{|c|}{$22.66 \pm 17.24$} \\
\hline \multicolumn{3}{|l|}{ Sex } \\
\hline Female & 3053 & 52.1 \\
\hline Male & 2810 & 47.9 \\
\hline Total & 5863 & 100.0 \\
\hline
\end{tabular}

Table 2: Mantoux reaction status of clients from 2011- 2017

\begin{tabular}{lll}
\hline Variable & Frequency $(\mathbf{N})$ & Percentage (\%) \\
\hline Reaction status $(\mathbf{m m})$ & & \\
No induration & 1964 & 33.5 \\
$1-4$ & 711 & 12.1 \\
$5-9$ & 767 & 13.1 \\
$\geq 10$ & 2421 & 41.3 \\
\hline Total & 5863 & 100.0 \\
\hline
\end{tabular}

Trend analysis of positive mantoux reaction by year 


\section{International Journal of Innovative Research in Medical Science (IJIRMS) Volume 04 Issue 01 Jan 2019, ISSN: 2455-8737, Imp. Factor - 4.102 Available online at $-\underline{w w w . i j i r m s . i n}$}

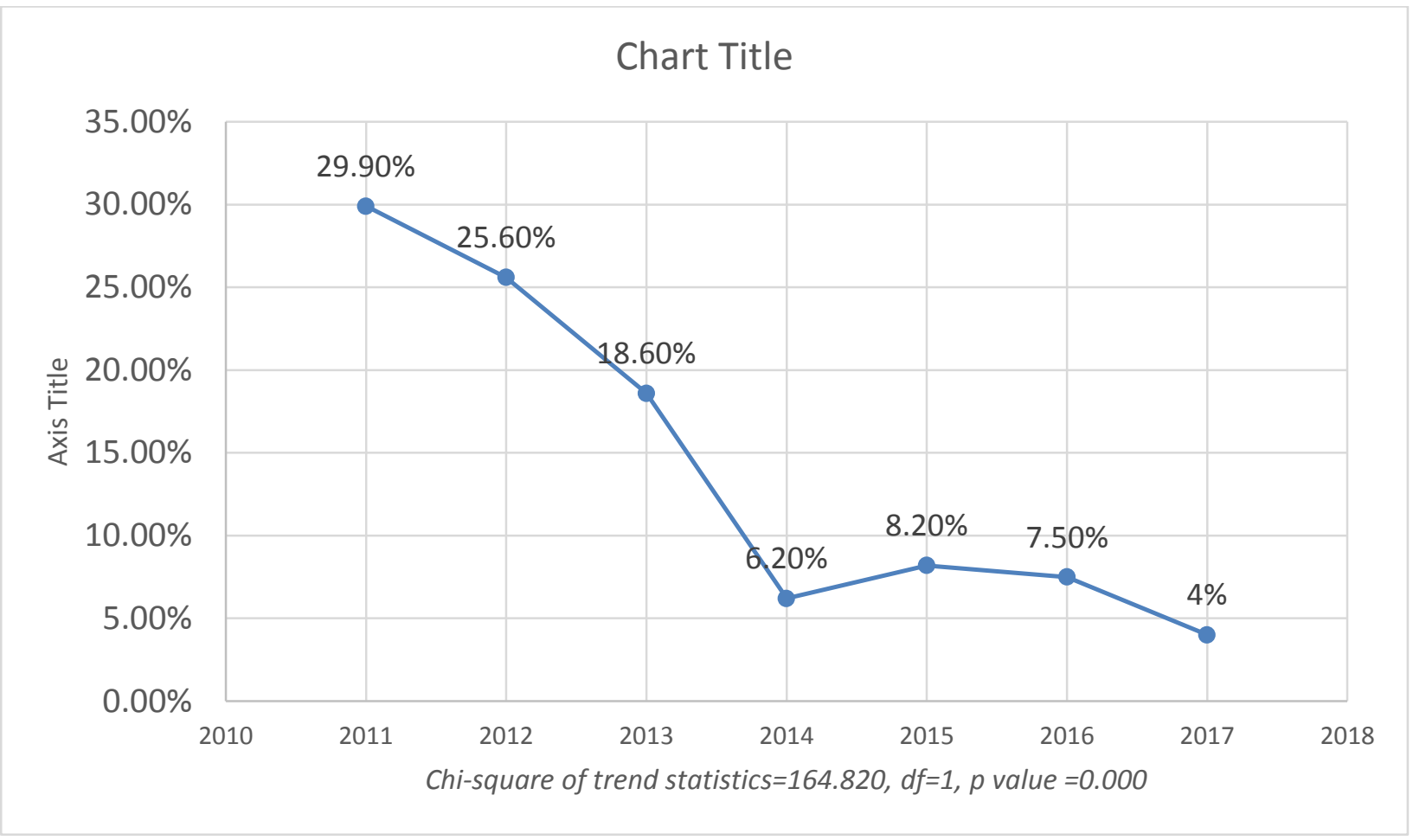

*statistically significant $(p<0.05)$

Figure 1: The $\chi^{2}$ (Chi-square) of trend of significant Mantoux reaction by year $(\geq 10 \mathrm{~mm})$

\section{Discussion}

\section{Tuberculin reaction status}

Mantoux test remains the widely used screening test to detect Latent tuberculosis infection (LTBI) in developing countries like Nigeria as LTBI poses a major challenge in the control of tuberculosis disease globally. Using a cut-off of $\geq 10 \mathrm{~mm}$ induration this study identified a prevalence of $41.3 \%$ positive Mantoux reaction. This corresponds to another report in this same region using data collected retrospectively and with similar sample size. Reporting for a five-year period, they found a positive Mantoux test prevalence of $47.8 \%$ (Okon et al., 2014) and lower than another similar study on pre-employment screening and contact tracing by Adeyekun et al., (2010) which reported slightly higher positive prevalence of $59.2 \%$ although with smaller sample size and more targeted population. Our result was also higher than the findings of Song et al., (2013) in a study conducted in Seoul, South Korea which reported mantoux prevalence of $36.5 \%$. The observed high prevalence of significant Mantoux test result in this study reestablished that there is a high LTBI prevalence and TB burden in Nigeria. And this underscores the necessity for intensive and continuous screening and treatment of LTBI as being critical to TB prevention and control in our region.

Trend of clients with significant tuberculin level $(\geq 10 \mathrm{~mm})$. The study modeled a seven-point trend line from 2011 to 2017. The aim was that historical modeling will allow our local set-up do assessments that will contribute towards making projections possibly involving the national TB program.

Chi square of trends assessed in this study indicated that there was a statistical significant decreasing proportion of positive Mantoux reaction status among clients across 2011-2017. The trend was towards continuous reduction in Mantoux test result positivity and suggesting a tailing of LTBI in this region. This may mean a number of things and also raise a number of questions. Such questions as "'Is there incident LTBI decline in our region?', Is our control programme yielding tangible results? Enabled and supported by the oil companies and NGOs in this region, the state government has made massive investments into medical care and socio economic development of the people. This result lends credence to a survey from Lima, Peru (Martinez et al., 2013) that linked declining TST positivity to improvement in social determinants of health. The WHO TB Country profile of 2016 and 2017 for Nigeria reported that funding has increased, treatment success rate has also increased steadily above $80 \%$. Incidence (new and relapse) are on a straight line, incidence (HIV and TB only) reducing over this period. Incidence of TB per 100000 was 322in 2015 to 219 in 2017. Our finding are in synergy with the findings of a study with similar sample size, conducted in South Korea, by Lee et al., (2014) which aimed at obtaining the baseline rate and trend of TST positivity in Korea and to ascertain whether LTBI is decreasing or not. Their findings indicated decline in trend of Mantoux positivity. Implication of decline in Mantoux positivity from this study shows there is need for continuous TB screening at every level of care.

\section{Conclusion}

For effective and efficient control of TB, Mantoux tuberculin skin test (TST) remain the standard tool to detect latent LTBI in Nigeria, and TST skin induration of $\geq 10 \mathrm{~mm}$ diameter is the cut-off point to identify a result that should be further evaluated with clerking, clinical examination and other investigations such as chest $\mathrm{x}$-ray. The overall profile of Mantoux test reaction from this study reveals a high positive Mantoux prevalence. However, when chi squared of trend for positive test was analyzed, there was an observed decline in the trend of significant Mantoux reaction over 


\section{International Journal of Innovative Research in Medical Science (IJIRMS) Volume 04 Issue 01 Jan 2019, ISSN: 2455-8737, Imp. Factor - 4.102 \\ Available online at $-\underline{w w w . i j i r m s . i n}$}

a period of 7 years. This is suggestive of a decline in the prevalence of LTBI and by proxy tuberculosis disease. Our report is in harmony with the global TB report 2017 which revealed that TB mortality rate fell by $37 \%$ and 53 million lives saved by TB treatment from 2000-2016.These findings further establish the need for intensified Public Health Education and mass campaign aimed at improving health seeking behavior, for early detection and treatment of LTBI as part of TB control strategies in Nigeria.

\section{Financial Support and Sponsorship}

The study was self-supported.

\section{Conflict of Interest}

None declared.

\section{Author's contribution}

GE designed the study, conducted the literature search and wrote up the work.

AT wrote up part of the manuscript and data analysis. INO designed the study, wrote up part of the manuscript and general supervision. All read the manuscript.

\section{References}

[1] Adeyekun AA, Egbagbe EE \& Oni OA (2010). Contact tracing/pre-employment screening for pulmonary tuberculosis: should positive Mantoux test necessitate routine chest X-ray? (Ann Afr Med.; 9 (3):159-63.

[2] Ahmad S, (2010). New approaches in the diagnosis and treatment of latent tuberculosis infection. Respir Res: 11:169.

[3] American Thoracic Society and CDC, (2000). Diagnostic standards and classification of tuberculosis in adults and children. Am J Respir Crit Care Med; 161:1376-95.

[4] Bluman, A.G, (2008). Elementary Statistics: A Step by Step Approach, Mcgraw Hill Companies, United States of America Page 7.

[5] Dye C, (2006). "Global epidemiology of tuberculosis," The Lancet, vol. 367, no. 9514, pp. 938-940, View at Publisher • View at Google Scholar • View at Scopus

[6] Fine PE, Bruce J, Ponnighaus JM, Nkhosa P, Harawa A, Vynnycky E. Tuberculin sensitivity: conversions and reversions in a rural African population. Int $\mathbf{J}$ Tuberc Lung Dis 1999; 3: 962-975.

[7] Ikuabe P. O., J. Jumbo, I. D. Ebuenyi \& E. A. Solomon, (2017). Comparison of Mantoux Reactivity in Smear Positive Pulmonary Tuberculosis Adults and Controls in Yenagoa, Nigeria, 22(4): 1-5, 2017; Article no.JAMMR.34166, ISSN: 2231-0614, NLM ID: 101570965

[8] Latent tuberculosis infection: Scaling up programmatic management of LTBI, a critical action to achieve the
WHO End TB Strategy targets. World Health Organization website. who.int/tb/publications/ltbi_factsheet_161014.pdf. Accessed September 11, 2017.

[9] Lee SW, Oh SY, Lee JB, Choi CM, Kim HJ (2014). Tuberculin Skin Test Distribution following a Change in BCG Vaccination Policy. PLoS ONE 9(1): e86419. doi:10.1371/journal.pone.0086419.

[10] Linas BP, Wong AY, Freedberb KA, Horsburgh CR Jr. (2011). Priorities for screening and treatment of latent tuberculosis infection in the United States. Am J Respir Crit Care Med.; 184(5):590-601. doi: 10.1164/rccm.201101-01810C.

[11] Martinez L, ArmanA, Havema N, Lundgren A, Cabrera L, Evans AC, Pelly TF. Changes in Tuberculin Skin Test Positivity over 20 years in Peri-urban shanty towns in Lima, Peru.Am J Trop Med HYG. 2013 4; 89(3): 507 515.

[12] Mancuso J, Diffenderfer J, Ghassemieh B, Horne D, Kao $\mathrm{T}$, (2016). The prevalence of latent tuberculosis infection in the United States. Am J Respir Crit Care Med.; 194(4):501-508. doi: 10.1164/rccm.201508-1683OC.

[13] Modu GM, Mohammed SG, Ashir MG, Adamu IR, (2009). Prevalence of Mantoux positivity among apparently health children in Maidugri, Nigeria. SA Journal of Child Health.; vol.3 NO.3

[14] Okon KO, Ajayi BB, Balogun ST, Adewolo K, Askira UM, Jibrin YB (2014). Retrospective analysis of positive Mantoux test in cases of suspected Mycobacterium tuberculosis infections seen at a tertiary hospital in Northeastern, Nigeria. American Journal of Research Communication.www.usa.journals.com

[15] Rieder HL, Chadha VK, Nagelkerke NJD, van Leth F, van der Werf MJ, (2011).Guidelines for conducting tuberculin skin test surveys in high-prevalence countries. Int J Tuberc Lung Dis ; 15:S1-26.

[16] TB elimination: the difference between latent $\mathrm{TB}$ infection and TB Disease. CDC website. cdc.gov/tb/publications/factsheets/general/ltbiandactivetb .htm. Published November 2011. Accessed September 9, 2016.

[17] Tuberculosis (TB): testing health care workers. CDC website. cdc.gov/tb/topic/testing/healthcareworkers.htm. Updated April 15, 2016. Accessed November15, 2017.

[18] World Health Organization (2014). Tuberculosis Fact sheet No.104 2014. Accessed on November 3, 2017

[19] World Health Organization (2016). Global Tuberculosis Report. http://www.who.int/tb/publications/global_report. Accessed October 7, 2017.

[20] World Health Organization (2017). Global Tuberculosis Report. http://www.who.int/tb/publications/global_report. Accessed December 24, 2017. 